\title{
Cooperativity Between Hydrogen- and Halogen Bonds: the Case of Selenourea
}

\author{
Gianluca Ciancaleoni*
}

Università degli Studi di Pisa, Dipartimento di Chimica e Chimica Industriale, via Giuseppe Moruzzi, 13 - 56124 Pisa, Italy.

*Email: gianluca.ciancaleoni@unipi.it, ORCID: 0000-0001-5113-2351

\begin{abstract}
A combined experimental/computational study of cooperativity between halogen- (XB) and hydrogen bonding (HB) is presented. The selenourea (SeU) has been chosen for its ability to act at the same time as $\mathrm{XB}$ acceptor toward $\mathrm{I}\left(\mathrm{CF}_{2}\right)_{5} \mathrm{CF}_{3}(\mathbf{I 1})$ through the two lone pairs on the selenium atom, and HB donor to the benzoate anion through its two amino moieties. All the equilibrium constants have been estimated using either diffusion NMR and NMR titrations techniques. Experimental results demonstrate that the $-\mathrm{NH}_{2} \cdots$ anion interaction strongly enhances the $\mathrm{Se}^{\cdots} \mathrm{I}$ one of about one order of magnitude (in terms of formation constant of the adduct), whereas DFT results rationalize such results revealing that the presence of a HB between the benzoate and SeU strongly polarizes the latter, enhancing the negative partial charge on the selenium and, consequently, its Lewis basicity and its $\mathrm{XB}$ acceptor properties.
\end{abstract}

\section{Introduction}

The halogen bond $(\mathrm{XB}),{ }^{1,2}$ which can be defined as the interaction between a Lewis base and a polarized halogen atom, has recently become a powerful tool in many fields of chemistry, from catalysis ${ }^{3,4}$ to biochemistry, ${ }^{5}$ but it plays a special role in the crystal engineering. ${ }^{6,7}$ Indeed, we can say that the "halogen bond adventure" officially started with the analysis of inter-molecular $\mathrm{Br}^{\cdots} \mathrm{O}$ distance in $\mathrm{Br}_{2} /$ dioxane co-crystal, ${ }^{8}$ in which this distance was less than the sum of the van der Waals radii. Still today, the analysis of X-ray (co)crystal structure is probably the best way to determine whether a XB is present or not.

But a crystal structure is determined by many different factors, and the possibility of an intermolecular interaction between two monomers is not enough to guarantee the existence of a co-crystal with the desired geometry: crystal packing, solubility and shape of the monomers are important factors, among others, for the final result. Another layer of complexity is added when the same pair of units have 
multiple interaction sites and are able to establish different interactions, such as XB and hydrogen bonds (HB).$^{9-11}$ Indeed, depending on subtle details of the interacting units, XB and HB can compete or cooperate each other, ${ }^{11}$

Moving from the solid state to solution ${ }^{12}$ has both pros and cons: the negative entropy of association excludes very weak intermolecular interactions. But the results are more systematic, since mass factors such as crystal packing are not present and only the molecular properties (beyond the properties of the chosen solvent, of course) determine the structure of the adduct. Moreover, quantitative studies are possible, allowing a more detailed and precise estimation of the cooperativity or synergy, if present. The main experimental techniques employed so far are the titration, ${ }^{13}$ to estimate the interaction energy, and the Job plot, to gain information about the stoichiometry of the adduct, which are fast and easy to perform, but not entirely reliable. ${ }^{14,15}$ In order to better describe the $\mathrm{XB}$ adduct in solution, it is important to use independent techniques that yield comparable information from a different point of view, such as Nuclear Overhauser Effect- ${ }^{16-18}$ and diffusion15,19,20 based NMR techniques. ${ }^{21}$ The coupling of different techniques, in fact, makes the picture clearer and more reliable.

Despite the impressive amount of literature devoted to the XB in solution, just a few papers quantify the mutual influence between XB and other noncovalent interactions. ${ }^{22,23}$ In one of them, Resnati and co-workers demonstrated that, using a neutral receptor able to bind at the same time an alkali cation and a XB-acceptor (as iodide), the coordination of $\mathrm{Na}^{+}$was greatly enhanced by the presence of a $\mathrm{XB} .{ }^{23}$ In another recent case, a similar behavior has been observed for a crown ether containing a iodo-triazole moiety: in this case the presence of a alkali metal in the crown ether makes the iodide iodo-triazole interaction much stronger. ${ }^{22}$

Conversely, from the theoretical point of view, the cooperativity of XB or between XB and HB has been studied many times, ${ }^{19,24-29}$ as there are fewer limitations about the quantification of very weak interaction energies and bond lengths (as far as the correct level of theory ${ }^{30,31}$ is used); moreover, various electronic analyses exist to get precious insight into the interaction and its contributions (among others, Energy Decomposition Analysis, ${ }^{32}$ Charge Displacement ${ }^{33,34}$ and Atoms In Molecule $\left.{ }^{35}\right)$.

In this paper, the cooperativity between $\mathrm{HB}$ and $\mathrm{XB}$ has been experimentally measured for selenourea. The latter has been chosen for its two-face structure: it bears a Lewis base, the lone pairs on the selenium atom, which can act as $\mathrm{XB}$ acceptor, two $-\mathrm{NH}_{2}$ groups, which can act as $\mathrm{HB}$ donors and, importantly, there is an electronic "communication" between the two moieties through resonance (Scheme 1). 


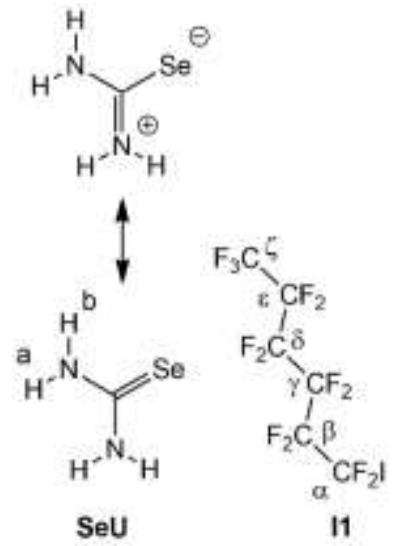

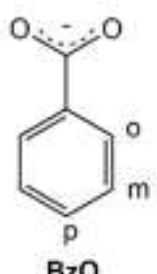

$\mathrm{BzO}$

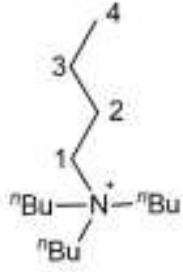

TBA

Scheme 1. Structure and assignation of molecular systems studied here. For the selenourea, the two most important resonance structures are shown.

Experimental results demonstrate that the $-\mathrm{NH}_{2} \cdots$ anion interaction strongly enhances the $\mathrm{Se}{ }^{\cdots} \mathrm{I}$ interaction by about one order of magnitude (in terms of formation constant of the adduct), whereas DFT results rationalize such results revealing that the presence of a HB between the benzoate and SeU strongly polarizes the latter, enhancing the negative partial charge on the selenium and, consequently, its Lewis basicity and its XB acceptor properties.

\section{Results and discussion}

Experimental studies. In order to study the mutual influence between hydrogen and halogen bonding, a molecular system containing both $\mathrm{HB}$ donor and $\mathrm{XB}$ acceptor groups is required, but many other experimental conditions have to be carefully optimized. Generally, the association constants for a XB adducts between two neutral species rapidly decrease as the polarity of the medium increases, ${ }^{36}$ even if not for all the $\mathrm{XB}$ interactions. ${ }^{37}$ On the other hand, the presence of $\mathrm{HB}$ donor groups reduces the solubility in apolar solvents, such as benzene and cyclohexane. 


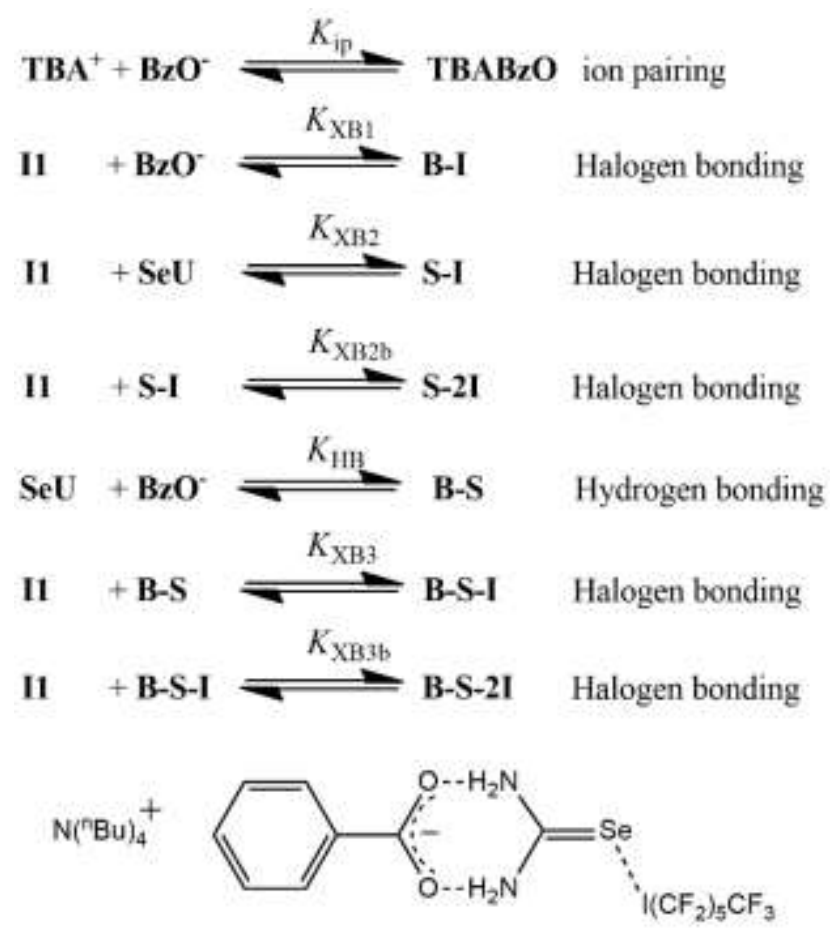

B-S-I

Scheme 2. List of all the interactions between the components and (below) the expected structure of B-S-I.

A convenient choice can be the selenourea (SeU) that possesses a $\alpha$-diamino moiety, which is a powerful HB donor, and two lone pairs on the selenium atom, which can act as XB acceptors. Unfortunately, the solubility of $\mathbf{S e U}$ in benzene, cyclohexane and chloroform was too low to allow a complete study. It can be brought into solution by establishing a HB with a soluble salt, such as tetrabutylammonium benzoate (TBABzO), but the XB could not be measured without the presence of the HB, as this study required. Indeed, the presence of perfluorohexyl iodide (I1) does not improve much the solubility of SeU in benzene.

Instead, acetone-d6 $\left(\varepsilon_{\mathrm{r}}=20.56\right.$ at $\left.20^{\circ} \mathrm{C}\right)$ has been used, as the solubility of all the species $(\mathbf{S e U}$, TBABzO and I1) is satisfactory, but it is not so polar to make the XB unmeasurable. For a detailed study, all the possible interactions should be evaluated (Scheme 2).

Since acetone is a solvent with intermediate polarity, the ion pairing process between benzoate and tetrabuylammonium cannot be totally neglected, ${ }^{38}$ as it can influence the hydrodynamic volume $\left(V_{\mathrm{H}}\right)$ of the benzoate anion, which is an important parameter for the diffusion NMR studies. For this reason, an evaluation of the ion pairing equilibrium constant of $\mathbf{T B A B z O}\left(K_{\mathrm{IP}}\right)$ is necessary. In order to do this, the best approach is measuring the trend of $V_{\mathrm{H}}$ of anion $\left(V_{\mathrm{H}^{-}}\right)$and cation $\left(V_{\mathrm{H}}{ }^{+}\right)$with their concentration by means of the diffusional Pulsed Field gradient Spin Echo (PGSE) NMR technique. ${ }^{39,40}$ For a $2.5 \mathrm{mM}$ solution of $\mathbf{T B A B z O}, V_{\mathrm{H}}{ }^{+}$and $V_{\mathrm{H}}{ }^{-}$result to be 470 and $270 \AA^{3}$, respectively (Table 1$)$. The former value is very close to the value for the naked cation $\left(V_{\mathrm{H}}{ }^{0+}\right),{ }^{41}$ 
indicating that under these conditions ion pairing is negligible, therefore we can use these values to calculate the hydrodynamic value of the ion pair $\left(V_{\mathrm{H}}^{0, \text { IP }}\right)$, which is $\left(V_{\mathrm{H}}^{0-}+V_{\mathrm{H}^{0+}}\right)=740 \AA^{3}$. At moderate concentration $(20.5 \mathrm{mM}) V_{\mathrm{H}^{-}}$and $V_{\mathrm{H}^{+}}$are 388 and $548 \AA^{3}$, respectively, values that are between the corresponding $V_{\mathrm{H}}{ }^{0+/-}$ and $V_{\mathrm{H}}$,IP , indication that just a portion of the ions are involved in ion pairs. Finally, increasing the concentration up to $185 \mathrm{mM}, V_{\mathrm{H}^{+}}$and $V_{\mathrm{H}^{-}}$result to be 760 and $579 \AA^{3}$, respectively (Table 1). The fact that $V_{\mathrm{H}^{+}}{ }^{+} V_{\mathrm{H}^{-}}$likely indicates that a small amount of triple ions containing two cations and one anion are present, which is not uncommon in acetone. ${ }^{38}$ Neglecting the triple ions as first approximation, $K_{\mathrm{IP}}$ can be roughly estimated from these data through the literature method ${ }^{41}$ as $22 \pm 10 \mathrm{M}^{-1}$.

Table 1. Diffusion coefficients $\left(D_{\mathrm{t}}^{+/-}, 10^{-10} \mathrm{~m}^{2} \mathrm{~s}^{-1}\right)$, hydrodynamic radii $\left(r_{\mathrm{H}}^{+/-}, \AA\right)$ and hydrodynamic volumes $\left(V_{\mathrm{H}^{+-}}, \AA^{3}\right)$ of $\mathbf{T B A B z O}$ in acetone at different concentrations $(C, \mathrm{mM})$.

\begin{tabular}{lllllll}
\hline$C$ & $D_{\mathrm{t}}^{+}$ & $D_{\mathrm{t}}^{-}$ & $r_{\mathrm{H}^{+}}$ & $r_{\mathrm{H}^{-}}$ & $V_{\mathrm{H}^{+}}$ & $V_{\mathrm{H}^{-}}$ \\
\hline 2.5 & 15.6 & 20.0 & 4.83 & 4.01 & 471 & 270 \\
20.5 & 14.5 & 16.9 & 5.08 & 4.53 & 548 & 388 \\
185 & 12.7 & 14.2 & 5.66 & 5.17 & 760 & 579 \\
\hline
\end{tabular}

The benzoate anion is expected to be a good XB acceptor, since XB between an anion and a suitable $\mathrm{XB}$ donor, as $\mathrm{I}\left(\mathrm{CF}_{2}\right)_{5} \mathrm{CF}_{3}(\mathbf{I} \mathbf{1})$ is, can be strong also in polar solvents. ${ }^{42}$ The corresponding association constant $\left(K_{\mathrm{XB} 1}\right)$ can be conveniently measured through a standard ${ }^{19} \mathrm{~F}$ NMR titration, keeping [I1] constant and monitoring the chemical shift of the $-\mathrm{CF}_{2} \mathrm{I}$ moiety $\left(\delta_{\alpha \mathrm{F}}\right)$ as a function of $\left[\mathbf{B z O}^{-}\right]$. Figure 1 shows the results and $\delta_{\alpha \mathrm{F}}$ passes from -65.1614 to $-77.0226 \mathrm{ppm}$ as $\left[\mathrm{BzO}^{-}\right]$passes from 0 to 74.7 $\mathrm{mM}$, respectively $([\mathbf{I 1}]=22.6 \mathrm{mM})$. The fitting of the experimental data leads to a $K_{\mathrm{XB} 1}=159 \pm 7 \mathrm{M}^{-}$ ${ }^{1}\left(\Delta \mathrm{G}^{0}=-3.0 \mathrm{kcal} / \mathrm{mol}\right)$.

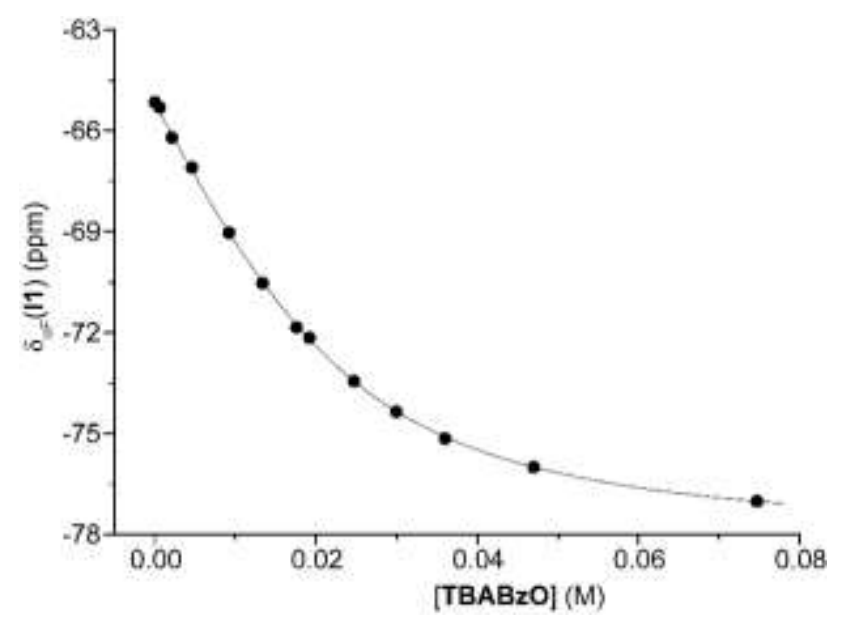


Figure 1. Trend of the chemical shift of the $\alpha$-fluorine nuclei $\left(-C F_{2} \mathrm{I}\right)$ of $\mathbf{I 1}(C=22.6 \mathrm{mM})$ with [TBABzO]. The solid line represents the best fit, with the limit value of $\delta_{\alpha \mathrm{F}}$ (fitted) $=-78.39 \pm 0.11$ ppm and $K_{\mathrm{XB} 1}=159 \pm 7 \mathrm{M}^{-1}$.

For the measurement of $K_{\mathrm{XB} 2}$ between $\mathrm{SeU}$ and I1, the situation is more complicated. In fact, [SeU] cannot be varied as freely as $\left[\mathbf{B z O}^{-}\right]$, because of its low solubility. One could think to keep constant [SeU], vary [I1] and analyze the trend of $\delta_{\mathrm{NH}}\left({ }^{1} \mathrm{H}\right.$ NMR titration), and, indeed, I1 has an effect on $\delta_{\mathrm{NH}}$. When $[\mathbf{I 1}]=0$ the signal due to the $\mathrm{NH}_{2}$ moiety is a broad singlet, while at high concentrations of [I1], two broad and overlapping signals appear $\left(\mathrm{NH}^{\mathrm{a}}\right.$ and $\mathrm{NH}^{\mathrm{b}}$, see Scheme 1 and Figure 2). Unfortunately, the small variation of $\delta_{\mathrm{NH}}$ and the broadness of the signals do not allow an accurate measurement of $K_{\mathrm{XB} 2}$. For this reason, the PGSE NMR technique has been used instead of the NMR titration. In particular, $V_{\mathrm{H}} \mathrm{SeU}$ has been monitored at different values of [I1] and it goes from 181 to $384 \AA^{3}$ when $[\mathbf{I 1}]=0$ and $931 \mathrm{mM}$ (Table 2), respectively. Since $V_{\mathrm{H}}{ }^{0}(\mathbf{I 1})=220 \AA^{3}{ }^{19}$ the hydrodynamic volume of the SeU-I1 adduct is $181+220=401 \AA^{3}$. Analyzing the trend of $V_{\mathrm{H}} \mathrm{SeU}_{v s}$. [I1], $K_{\mathrm{XB} 2}$ can be estimated. Fitting the experimental data with the 1:1 model, $K_{\mathrm{XB} 2}$ results to be 5.0 $\pm 0.8 \mathrm{M}^{-1}$ (Figure 2) but the absence of a clear plateau at high concentrations of [I1] can be an indication that a second molecule of $\mathbf{I 1}$ can bind the selenium through the second lone pair of the latter (adduct S-2I, Scheme 2). ${ }^{19}$ Using the 1:2 model with $K_{\mathrm{XB} 2}=4.4 \pm 0.2 \mathrm{M}^{-1}\left(\Delta \mathrm{G}^{0}=-0.88 \mathrm{kcal} / \mathrm{mol}\right)$ and $K_{\mathrm{XB} 3}=0.19 \pm 0.03 \mathrm{M}^{-1}\left(\Delta \mathrm{G}^{0}=0.98 \mathrm{kcal} / \mathrm{mol}\right)$, the quality of the fit sensibly improves, even if considering a $10 \%$ of uncertainty on the hydrodynamic volumes, both the models could be acceptable (Figure 2).
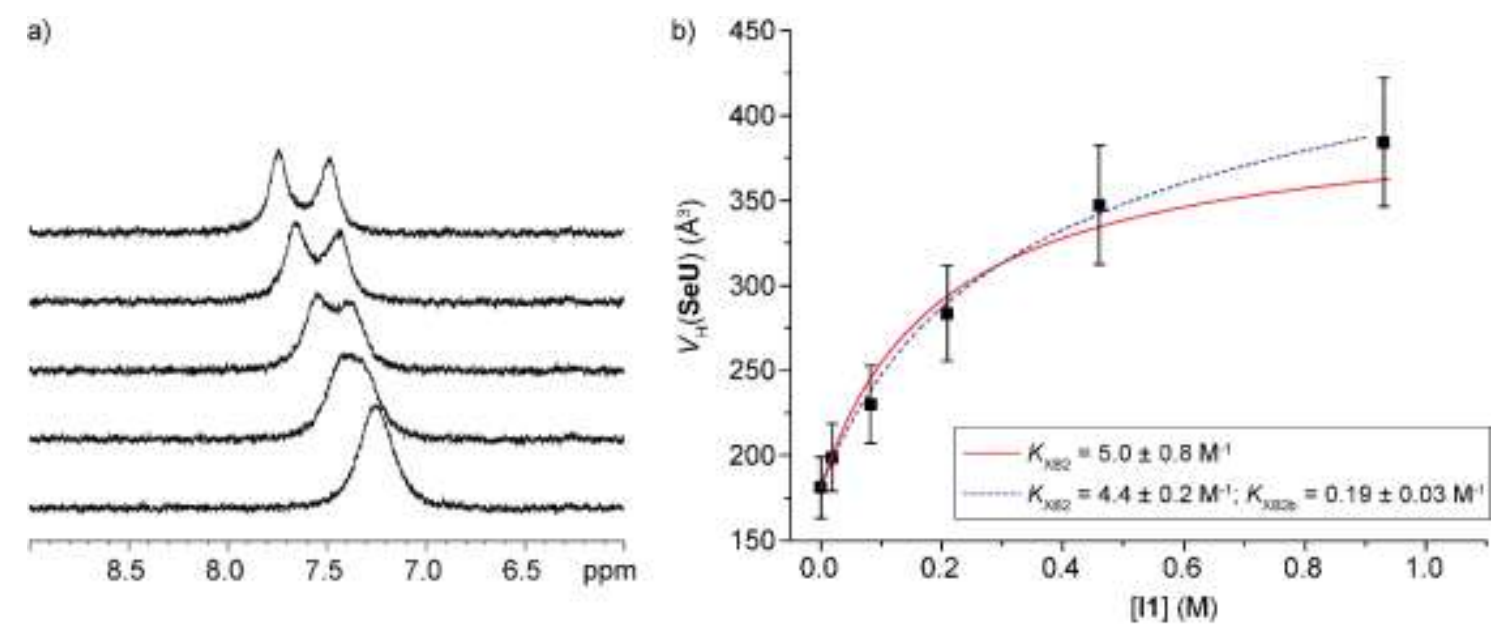

Figure 2. a) Stacked ${ }^{1} \mathrm{H}$ NMR spectra of solutions containing SeU (16 mM) and increasing amounts of I1 (from bottom to top: 0, 19, 82, 209 and $460 \mathrm{mM}$, solvent: acetone-d6); b) Experimental 
hydrodynamic volume of SeU $(C=16 \mathrm{mM})$ at different concentrations of I1. The two lines represent the best fits obtained with the 1:1 model (solid red line) or the 1:2 (dashed blue line).

Table 2. Diffusion coefficients $\left(D_{\mathrm{t}}^{+/-}, 10^{-10} \mathrm{~m}^{2} \mathrm{~s}^{-1}\right)$, hydrodynamic radii $\left(r_{\mathrm{H}}^{+/-}, \AA\right)$ and hydrodynamic volumes $\left(V_{\mathrm{H}}^{+-}, \AA^{3}\right)$ of SeU in acetone-d6 at different concentrations of [I1] $(C, \mathrm{mM})$.

\begin{tabular}{llll}
\hline$C$ & $D_{\mathrm{t}}$ & $r_{\mathrm{H}}$ & $V_{\mathrm{H}}^{\text {SeU }}$ \\
\hline 0 & 24.4 & 3.51 & 181 \\
19 & 23.4 & 3.62 & 199 \\
82 & 21.7 & 3.80 & 230 \\
209 & 19.6 & 4.08 & 283 \\
460 & 17.8 & 4.36 & 347 \\
931 & 17.0 & 4.51 & 384 \\
\hline
\end{tabular}

The HB between $\mathbf{S e U}$ and $\mathbf{B z O}^{-}$is expected to be very strong because of the perfect geometrical matching between the carboxylate moiety and the $\mathrm{HN}-\mathrm{C}-\mathrm{NH}$ fragment. And, indeed, such interaction has been extensively used and studied. ${ }^{43,44}$ As in the case of $\mathbf{S}$-I, the broad signal due to the four NH moieties decoalesces into two broad signals in the presence of $\mathbf{B z O}^{-}$. In this case, the effect is much larger (from 7.26 to $11.31 \mathrm{ppm}$ and from 7.26 to 6.55 for $\mathrm{NH}^{\mathrm{a}}$ and $\mathrm{NH}^{\mathrm{b}}$, respectively, Figure 3), the signals are narrower and $\delta_{\mathrm{NH}}$ can be used for a ${ }^{1} \mathrm{H}$ NMR titration. The large differentiation of $\mathrm{NH}^{\mathrm{a}}$ and $\mathrm{NH}^{\mathrm{b}}$ is due to the fact that in the $\mathbf{B}-\mathbf{S}$ the amine groups cannot rotate as rapidly as in the isolated SeU. Nonetheless, the exchange between $\mathrm{NH}^{\mathrm{a}}$ and $\mathrm{NH}^{\mathrm{b}}$ is still too fast to be measured by ${ }^{1} \mathrm{H}$ EXSY NMR.

The fitting of the experimental data leads to a $K_{\mathrm{HB}}$ of $1582 \pm 300 \mathrm{M}^{-1}\left(\Delta \mathrm{G}^{0}=-4.4 \mathrm{kcal} / \mathrm{mol}\right)$, if $\delta_{\mathrm{NHa}}$ is used, or $1312 \pm 700 \mathrm{M}^{-1}$, if $\delta_{\mathrm{NHb}}$ is used. $K_{\mathrm{HB}}$ is sensibly stronger than the previously determined halogen bonding association constants. This means that if all the species are in solution, $\mathbf{B z O}^{-}$will tend to saturate the SeU, firstly, and then, if still available, it will interact with $\mathbf{I 1}$. 

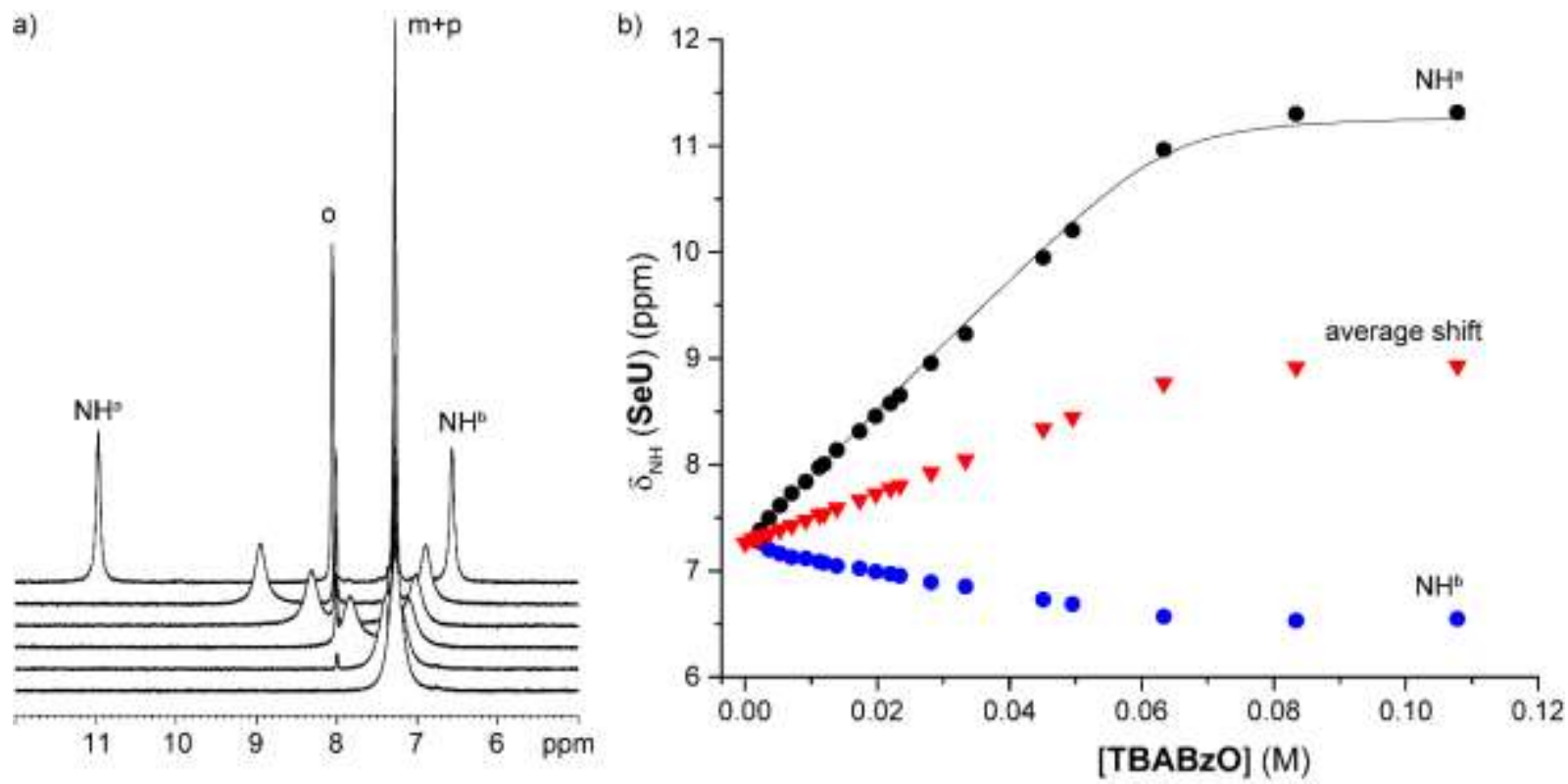

Figure 3. a) Stacked ${ }^{1} \mathrm{H}$ NMR spectra of solutions containing SeU (64 mM) and increasing amounts of TBABzO (from bottom to top: 0, 2.3, 9.2, 17.4, 28.2 and $63.4 \mathrm{mM}$, solvent: acetone-d6); b) trend of the chemical shift of the NHs of $\mathbf{S e U}(C=64 \mathrm{mM})$ with [TBABzO]. The solid line represents the best fit, with the limit value of $\delta_{\mathrm{NHa}}($ imposed $)=11.31 \mathrm{ppm}$ and $K_{\mathrm{HB}}($ fitted $)=1582 \pm 335 \mathrm{M}^{-1}$.

Now that all the two-components interactions have been characterized, the three-components $\mathrm{XB}$, involving TBABzO, SeU and $\mathbf{I} 1$ can be faced. As underlined before and as it was expected, $K_{\mathrm{HB}} \gg$ $K_{\mathrm{XB} 1}$, therefore mixing the three components together will firstly lead to the formation of $\mathbf{B}-\mathbf{S}\left(\mathbf{B z O}^{-}\right.$ $+\mathbf{S e U}$ ), which, in its turn, can interact with $\mathbf{I}$ giving B-S-I. But, also in this case, the method to measure the value of $K_{\mathrm{XB} 3}$ requires a careful analysis of the system. Firstly, whichever experimental parameter will be followed, it is evident that the only practical way to perform a titration is to keep constant [B-S] and increase [I1]; secondly, the ideal parameter should be involved only in the species B-S and B-S-I, in order to avoid complex fitting procedures.

Considering the values of all the formation constants previously measured, a convenient strategy is to use an excess of $\mathbf{T B A B z O}$ with respect to $\mathbf{S e U}$ and increase [I1]. In such a way, given the large value of $K_{\mathrm{HB}}$, it can be assumed that practically all the molecules of $\mathbf{S e U}$ will be involved in B-S. The excess of $\mathbf{B z O}^{-}$will be partially present as free ions, partially involved in ion pairs and partially involved in B-I. This makes any property related to $\mathbf{B z O}^{-}$too complex to be used. Similar considerations can be applied to I1: either in excess or defect, its tendency to associate with either free $\mathbf{B z O}^{-}$and $\mathbf{B}-\mathbf{S}$ makes its properties $\left(V_{\mathrm{H}}\right.$ and $\left.\delta_{\alpha \mathrm{F}}\right)$ hardly usable to extract information about the $\mathrm{Se}^{\cdots} \mathrm{I}$ interaction.

The only other chemical species is $\mathbf{S e U}$, which is present only in $\mathbf{B}-\mathbf{S}$ and whose properties can be monitored at different values of [I1], and the use of $V_{\mathrm{H}}{ }^{\mathrm{SeU}}$ is the most convenient strategy. ${ }^{45}$ 
Given the structure of the selenourea, $V_{\mathrm{H}}$ SeU can be evaluated only using the NH peaks, but the intensity of the latter does not decrease monoexponentially with the squared gradient of the magnetic field $\left(G^{2}\right)$, as it generally is (see Experimental Section and Supporting Information). Rather, the trend is biexponential, indication that the peak contains information about two chemical species which exchange each other but not so rapidly to give a monoexponential decay. For example, for a solution containing SeU (32 mM), TBABzO $(74 \mathrm{mM})$ and I1 (16 mM), the PGSE NMR experiment gives two diffusion coefficients for $\mathrm{NH}^{\mathrm{a}}, 12.5 * 10^{-10}$ and $57.5 * 10^{-10} \mathrm{~m}^{2} \mathrm{~s}^{-1}$. The former is compatible with a B-S-containing adduct (the $D_{\mathrm{t}}(\mathbf{B}-\mathbf{S})$ when $[\mathbf{I 1}]=0 \mathrm{mM}$ is $14.5 * 10^{-10} \mathrm{~m}^{2} \mathrm{~s}^{-1}$ ), while the latter refers to a very small species, even smaller than the solvent (the $D_{\mathrm{t}}$ of pure acetone-d6 is $42.6 * 10^{-10} \mathrm{~m}^{2} \mathrm{~s}^{-}$ ${ }^{1}$ ). The only plausible species is water, and, indeed, performing a ${ }^{1} \mathrm{H}$ EXSY NMR (Figure 4), is confirmed that $\mathrm{NH}^{\mathrm{a}}$ is in exchange not only with $\mathrm{NH}^{\mathrm{b}}$, because of the rotation of the $\mathrm{C}-\mathrm{N}$ bond of the selenourea, but also with water, whose peak is severely broadened and located at $4.11 \mathrm{ppm}$ (with [I1] $=0 \mathrm{mM}, \delta\left(\mathrm{H}_{2} \mathrm{O}\right)=3.35 \mathrm{ppm}$ and the peak is less broad, in the absence of other species in solution, $\delta\left(\mathrm{H}_{2} \mathrm{O}\right)$ in acetone is around $\left.2.83 \mathrm{ppm}\right)$.

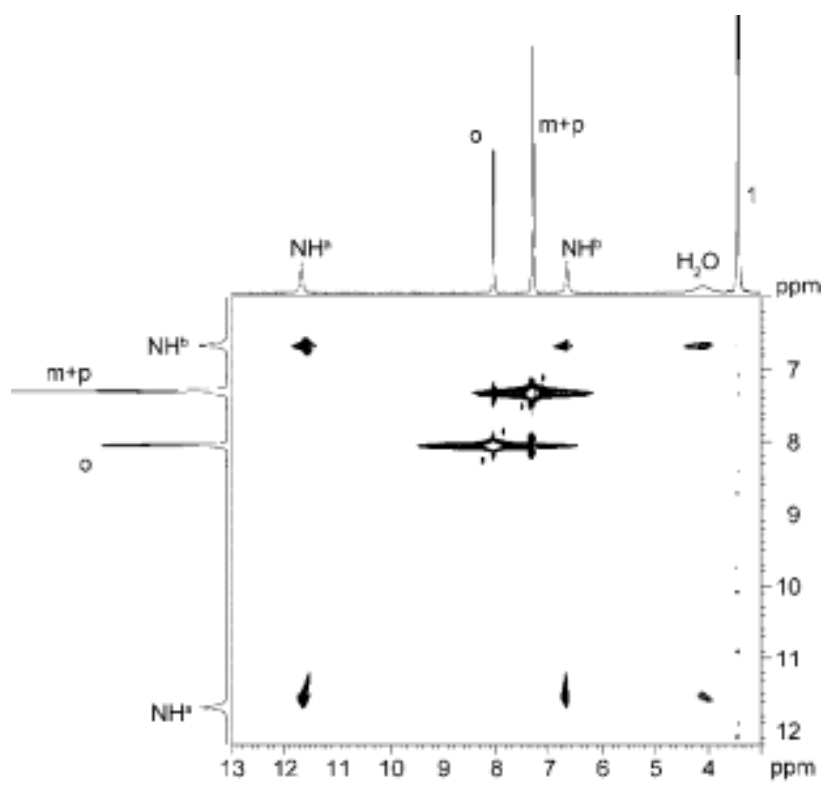

Figure 4. Section of the ${ }^{1} \mathrm{H}$ EXSY spectrum of SeU+TBABzO+I1 (acetone-d6, T = $298 \mathrm{~K}$, mixing time $400 \mathrm{~ms})$.

Focusing on the lower value of $D_{\mathrm{t}}$ derived from the biexponential fit of the PGSE data (see Supporting Information), $V_{\mathrm{H}}^{\mathrm{SeU}}$ increases from 536 to $789 \AA^{3}$ for [I1] $=0$ and $248 \mathrm{mM}$, respectively (Table 3). Considering that the expected hydrodynamic volume of B-S-I is $536+220=756 \AA^{3}$, a volume of $789 \AA^{3}$ indicates that, as for SeU + I1 (Figure 2), 1:2 stoichiometry could be taken into account. 
Table 3. Diffusion coefficients $\left(D_{\mathrm{t}}^{+/-}, 10^{-10} \mathrm{~m}^{2} \mathrm{~s}^{-1}\right)$, hydrodynamic radii $\left(r_{\mathrm{H}}^{+/-}, \AA\right)$ and hydrodynamic volumes $\left(V_{\mathrm{H}}^{+-}, \AA^{3}\right)$ of $\mathbf{S e U}$ in acetone-d6 at different concentrations of $[\mathbf{I 1}](C, \mathrm{mM})$. [TBABzO$]=$ $72 \mathrm{~m}$.

\begin{tabular}{llll}
\hline$C$ & $D_{\mathrm{t}}$ & $r_{\mathrm{H}}$ & $V_{\mathrm{H}}^{\mathrm{SeU}}$ \\
\hline 0 & 14.5 & 5.04 & 536 \\
16.0 & 13.9 & 5.25 & 606 \\
30.0 & 13.5 & 5.37 & 649 \\
52.8 & 13.2 & 5.50 & 697 \\
248 & 12.5 & 5.74 & 792 \\
\hline
\end{tabular}

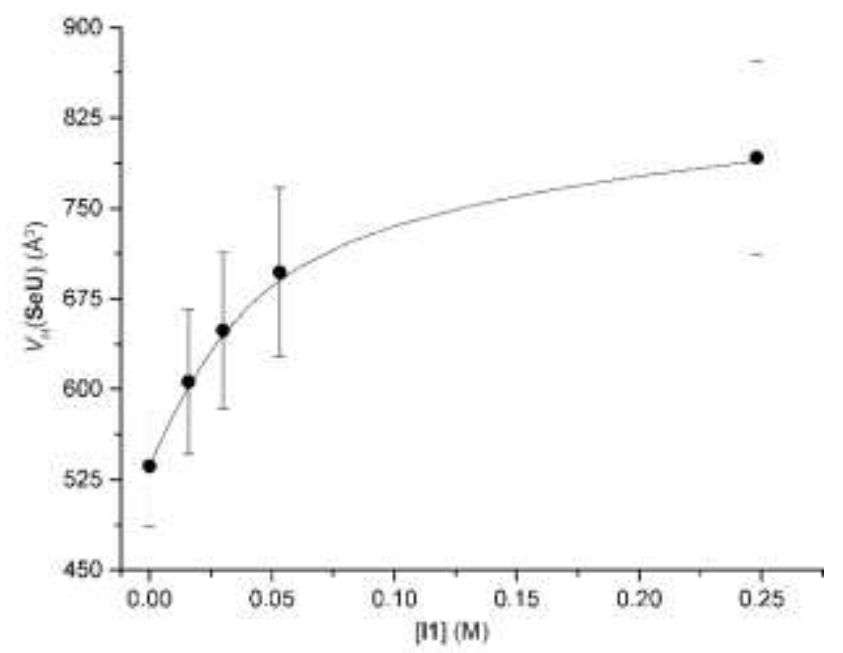

Figure 5. Experimental hydrodynamic volume of SeU at different concentrations of I1. The solid line represents the best fit obtained with the 1:2 model, $K_{\mathrm{XB} 3}=65 \pm 3 \mathrm{M}^{-1} ; K_{\mathrm{XB} 3 \mathrm{~b}}=1.3 \pm 0.3 \mathrm{M}^{-1}$.

Fitting the values of $V_{\mathrm{H}}^{\mathrm{SeU}}$ vs. [I1], $K_{\mathrm{XB} 3}$ results to be $65 \mathrm{M}^{-1}\left(\Delta \mathrm{G}^{0}=-2.5 \mathrm{kcal} / \mathrm{mol}\right)$ and $K_{\mathrm{XB} 3 \mathrm{~b}} 1.3 \mathrm{M}^{-}$ ${ }^{1}\left(\Delta \mathrm{G}^{0}=-0.15 \mathrm{kcal} / \mathrm{mol}\right.$, Figure 5$)$, which are one order of magnitude larger than $K_{\mathrm{XB} 2}$ and $K_{\mathrm{XB} 2 \mathrm{~b}}(4.4$ and $0.19 \mathrm{M}^{-1}$, see Figure 2), revealing a nice reinforcement effect between the two interactions. In terms of free energy, the interaction between the selenium and the first molecule of $\mathbf{I 1}$ is boosted three-fold with respect to the situation without the HB (from 0.88 to $2.5 \mathrm{kcal} / \mathrm{mol}$ ) whereas the free energy between the selenium and the second molecule of $\mathbf{I 1}$ becomes negative instead of positive, indicating that now even the 1:2 adduct is thermodynamically favored.

In the next section, different theoretical tools will be used to shed light on the origin of such effect.

Computational studies. The adducts experimentally evidenced have been optimized by using the BP86 D3 functional and the energies of the optimized geometries have been successively evaluated 
by the M062X functional and the same basis set, which already proved to be a good choice for XB adducts. ${ }^{30}$ To save computational resources, the fluorinated chain has been substituted with a single $-\mathrm{CF}_{3}$ moiety.

As shown in Table 4, the solvent-corrected interaction energy (gas-phase values can be found in Table S3, Supporting Information) between $\mathbf{S e U}$ and $\mathrm{ICF}_{3}\left(\mathbf{I}_{\mathbf{m}}\right)$ is $-11.3 \mathrm{kcal} / \mathrm{mol}$, whereas between $\mathbf{S e U}$ and $\mathbf{B z O}^{-}$is, as expected, stronger $(-15.6 \mathrm{kcal} / \mathrm{mol})$ and the interaction energy between $\mathbf{B z O}^{-}$and $\mathbf{I C F}_{3}$ is $-9.8 \mathrm{kcal} / \mathrm{mol}$ (Table 4).

Table 4. Interaction energy (in $\mathrm{kcal} / \mathrm{mol}$ ), thermodynamic parameters and bond lengths (in $\AA$ ) for the different adducts at M06-2X/aug-TZVP//BP86-D3/aug-TZVP level (solvent taken into accout using the PCM model). The parenthesis indicate that the interaction energy is referred to the pre-formed binary adduct rather than the three isolated components.

\begin{tabular}{lllllll}
\hline Adduct & $\Delta E$ & $\Delta H^{\mathrm{a}}$ & $\Delta S^{\mathrm{a}}$ & $\Delta G^{\mathrm{a}}$ & $\mathrm{C}-\mathrm{Se}$ & $\mathrm{C}-\mathrm{N}$ \\
\hline SeU & - & - & - & - & 1.830 & 1.366 \\
S-Im & -11.3 & -11.0 & -10.3 & -0.75 & 1.855 & $1.351^{\mathrm{b}}$ \\
$\mathbf{B - S}$ & -15.6 & -17.5 & -14.1 & -1.75 & 1.881 & 1.344 \\
B-Im & -9.8 & -9.6 & -13.2 & 3.59 & - & - \\
B-S-Im & -28.2 & -30.0 & -29.3 & -0.73 & 1.903 & $1.334^{\mathrm{b}}$ \\
(B-S)-Im & -12.6 & -12.5 & -13.5 & 1.03 & - & - \\
B-(S-Im) & -16.9 & -19.0 & -19.0 & 0.03 & - & -
\end{tabular}

${ }^{\mathrm{a}}$ Calculated at $298 \mathrm{~K} ;{ }^{\mathrm{b}}$ Averaged between the two $\mathrm{CN}$ bonds

For the three-body adduct B-S-Im, the total interaction energy (with respect to the three isolated components) is $-28.2 \mathrm{kcal} / \mathrm{mol}(\Delta G=-0.73 \mathrm{kcal} / \mathrm{mol})$, whereas, with respect to the pre-formed $\mathbf{B}-\mathbf{S}$ and the isolated $\mathbf{I}_{\mathbf{m}}$, it is $-12.6 \mathrm{kcal} / \mathrm{mol}$, which is larger than the interaction energy for $\mathbf{S}-\mathbf{I}_{\mathbf{m}}(-11.3$ $\mathrm{kcal} / \mathrm{mol}$ ) The ratio between the two energies is 1.12 and this is an useful parameter to indicate the magnitude of the synergetic effect. ${ }^{46}$ Therefore, the presence of a reinforcing effect of $\mathrm{HB}$ on $\mathrm{XB}$ is confirmed also theoretically.

Interestingly, a similar effect can be observed using as reference the pre-formed $\mathbf{S}-\mathbf{I}_{\mathbf{m}}$ and the isolated $\mathbf{B}$ : the interaction energy is $-16.9 \mathrm{kcal} / \mathrm{mol}$, larger than the interaction energy in $\mathbf{B}-\mathbf{S}(-15.6 \mathrm{kcal} / \mathrm{mol})$. In this case the ratio is 1.08 , again larger than 1 (reinforcing effect), but smaller than in the previous case, indication that the synergetic effect of the $\mathrm{HB}$ on the $\mathrm{XB}$ is larger than that of the $\mathrm{XB}$ on the HB. 
In order to establish whether the reinforcing effect can be really considered cooperative, the cooperativity energy can be calculated from the data listed in Table 4 . They can be defined as in the literature, using Eq. (1). ${ }^{46}$

$$
E_{\mathrm{coop}}=E_{\mathrm{B}-\mathrm{S}-\mathrm{Im}}-E_{\mathrm{B}-\mathrm{S}}-E_{\mathrm{S}-\mathrm{Im}}-E_{\mathrm{B}-\mathrm{Im}}
$$

where $E_{\mathrm{B}-\mathrm{S}-\mathrm{Im}}$ is the interaction energy of the optimized ternary adduct $\mathbf{B}-\mathbf{S}-\mathbf{I}_{\mathbf{m}}, E_{\mathrm{B}-\mathrm{S}}$ and $E_{\mathrm{S}-\mathrm{Im}}$ are the interaction energies of the optimized binary adducts $\mathbf{B}-\mathbf{S}$ and $\mathbf{S}-\mathbf{I}_{\mathbf{m}}$, respectively, and $E_{\mathrm{B}-\mathrm{Im}}$ is the energy of the non-optimized binary adduct $\mathbf{B}-\mathbf{I}_{\mathbf{m}}$, in the geometry they have in the ternary adduct but in the absence of the $\mathbf{S}$ moiety. $E_{\text {coop }}$ results to be $-4.2 \mathrm{kcal} / \mathrm{mol}$ and the negative sign confirms the cooperativity between the two weak interactions.

The length of the C-Se bond seems to be a probe that is sensitive to the presence and magnitude of weak interactions: starting from $1.830 \AA$ (isolated SeU), it increases to $1.855 \AA$ when the selenium is involved in a XB with $\mathbf{I}_{\mathbf{m}}$, to $1.881 \AA$ when the benzoate establishes a HB with the NH-C-NH moiety of SeU and to $1.903 \AA$ when both the interactions are present, showing also in this sense a nice cooperativity.

The C-N bond length, on the other hand, reacts in the opposite direction, as it shortens from 1.366 to 1.345/1.357 A for the isolated SeU and the S-Im adduct, respectively (the C-N bond that points toward the $\mathrm{ICF}_{3}$ is more sensitive than the other, likely for electrostatic reasons). A similar effect is given by the $\mathrm{HB}$ with the benzoate $(\mathrm{C}-\mathrm{N}=1.344 \AA)$ and the combination of the two effects is, again, cooperative $(\mathrm{C}-\mathrm{N}=1.331 / 1.337 \AA$ ). It appears evident that weak interactions modify the relative importance of the two resonance structures of SeU (Scheme 1). In particular, both, the HB and the $\mathrm{XB}$ increase the importance of the ionic structure.

Natural Population Analysis (NPA) charges, NBO second-order perturbation theory interaction energy analysis and the Mayer bond orders ${ }^{47}$ (Table 5) are coherent with the framework described above. In particular, the negative charge on the selenium atom decreases from -0.249 to -0.218 e for SeU and $\mathbf{S}-\mathbf{I}_{\mathbf{m}}$, respectively, indication that the selenium is donating electronic charge to the iodine $(\mathrm{XB})$, and the C-Se bond order $\left(n_{\mathrm{CSe}}\right)$ decreases from 1.70 to 1.48 for the same systems, confirming that the $\mathrm{C}$-Se bond becomes more similar to a single bond as the XB is established, as already noted discussing the $\mathrm{C}$-Se distances. The strength of the donor-acceptor $(\mathrm{D} \rightarrow \mathrm{A})$ interaction between the lone pair of the selenium and the $\sigma^{*}$ orbital of the $\mathrm{C}$-I bond, $E^{(2)}\left(l_{\mathrm{Se}} \rightarrow \sigma^{*} \mathrm{IC}\right)$, amounts to $25 \mathrm{kcal} / \mathrm{mol}$ in the $\mathbf{S}-\mathbf{I}_{\mathbf{m}}$ adduct (more $E^{(2)}$ values can be found in the Supporting Information). For the diamino moiety, $n_{\mathrm{CN}}$ slightly increases from 1.20 to 1.25 as a consequence of the $\mathrm{XB}$, confirming the existence 
of an electronic communication between the two moieties. Interestingly, the Mayer bond order for the $\mathrm{Se}^{\cdots} \mathrm{I}$ bond is 0.22 .

In the case of B-S, $n_{\mathrm{CSe}}$ decreases down to 1.432 and $q_{\mathrm{Se}}$ is -0.484 e: the HB between the benzoate and the selenourea polarizes the latter and makes the selenium more negatively charged and, consequently, a better XB acceptor, coherently with the experimental and theoretical results about the $\mathrm{XB}$ energy. The effect of the $\mathrm{HB}$ on $n_{\mathrm{CN}}$ is quite large and the latter increases up to 1.32.

Finally, combining the two interactions (B-S-Im adduct), $q_{\mathrm{Se}}$ becomes -0.325 e, lower than in the case of $\mathbf{B}-\mathrm{S}$ because of the $\mathrm{Se} \rightarrow$ I charge transfer, whereas $n_{\text {CSe }}$ decreases down to 1.25 and $n_{\text {SeI }}$ becomes 0.40, almost twofold larger than in the case of $\mathbf{S}-\mathbf{I}_{\mathbf{m}}$. Coherently, $E^{(2)}\left(l p_{\mathrm{Se}} \rightarrow \sigma^{*} \mathrm{IC}\right)$ is $50.9 \mathrm{kcal} / \mathrm{mol}$, twofold the energy calculated in $\mathbf{S}-\mathbf{I}_{\mathbf{m}}$. Conversely, $n_{\mathrm{CN}}$ is 1.36 , even larger than in the case of $\mathbf{B}-\mathbf{S}$.

Table 5. NPA charges ( $q$, in e), second-order perturbation stabilization energies $\left(E^{(2)}\right.$, in $\left.\mathrm{kcal} / \mathrm{mol}\right)$ for the $\mathrm{D} \rightarrow \mathrm{A}$ NBO interaction $l p_{\mathrm{Se}} \rightarrow \sigma^{*} \mathrm{IC}$ and Mayer bond order $(n)$ for the different adducts at M06-2X/aug-TZVP//BP86-D3/aug-TZVP level.

\begin{tabular}{ccccccc}
\hline Adduct & $q_{\mathrm{Se}}$ & $q_{\mathrm{N}}$ & $E^{(2)}$ & $n_{\mathrm{CSe}}$ & $n_{\mathrm{CN}^{\mathrm{a}}}$ & $n_{\mathrm{SeI}}$ \\
\hline SeU & -0.249 & -0.805 & - & 1.70 & 1.20 & - \\
$\mathbf{S}-\mathbf{I}_{\mathbf{m}}$ & -0.218 & -0.791 & 25.0 & 1.48 & 1.25 & 0.22 \\
$\mathbf{B}-\mathbf{S}$ & -0.484 & -0.823 & - & 1.43 & 1.32 & - \\
B-S-Im & -0.325 & -0.809 & 50.9 & 1.25 & 1.36 & 0.40 \\
\hline
\end{tabular}

${ }^{a}$ Averaged value between the two $\mathrm{CN}$ bonds.

Other D $\rightarrow$ A NBO interactions (see Table S4, Supporting Information) are interesting to be discussed: 1) $E^{(2)}\left(l_{p_{\mathrm{O}}} \rightarrow \sigma^{*} \mathrm{NH}\right)$, which describes the HB between the benzoate and the selenourea, passes from 13.5 to $20.8 \mathrm{kcal} / \mathrm{mol}$ for $\mathbf{B}-\mathbf{S}$ and $\mathbf{B}-\mathbf{S}-\mathbf{I}_{\mathbf{m}}$, respectively, highlighting again that the influence is mutual and the presence of the XB enhances the HB strength, even if on a smaller degree;

2) $E^{(2)}\left(l p_{\mathrm{I}} \rightarrow \sigma^{*} \mathrm{NH}\right)$, which describes an additional component of the $\mathbf{S e U} \cdots \mathbf{I}_{\mathbf{m}}$ interaction consisting in a weak HB between the lone pair of the iodine and the amino moiety of SeU. Such component is 4.51 for $\mathbf{S}-\mathbf{I}_{\mathbf{m}}$, but only $1.80 \mathrm{kcal} / \mathrm{mol}$ in $\mathbf{B}-\mathbf{S}-\mathbf{I}_{\mathbf{m}}$, likely because the amino moiety, which is already interacting with the benzoate anion, is less prone to form a second $\mathrm{HB}$ ( $\mathrm{HB} / \mathrm{HB}$ anti-cooperativity).

\section{Conclusions}

In this work a combined experimental/theoretical study on the cooperativity between hydrogen- and halogen bond is presented, using the selenourea as case of study and making it interact with a HBacceptor, as the benzoate anion, and a XB-donor, as I1. Considering all the species involved, 
including the cation of the benzoate, many equilibria coexist in solution, but varying and optimizing the experimental conditions, all the constants can be estimated through ${ }^{1} \mathrm{H}$ or ${ }^{19} \mathrm{~F}$ NMR titrations or PGSE NMR experiments. The results evidenced that the interaction between the benzoate and the amino groups of the selenourea makes the interaction between the selenium and the iodine of $\mathbf{I 1}$ much stronger $\left(\Delta \mathrm{G}^{0}\right.$ from -0.88 to $-2.5 \mathrm{kcal} / \mathrm{mol}$ in the absence and presence of the benzoate, respectively). Not only, but also the interaction with two molecules of $\mathbf{I 1}$ is favoured by the presence of the salt, with the corresponding $\Delta \mathrm{G}^{0}$ value that passes from positive to negative, from 0.98 to $-0.15 \mathrm{kcal} / \mathrm{mol}$. Theoretical investigations reproduced the experimental trend and the cooperativity between the two interactions. More importantly, the C-Se and C-N bond orders, estimated either from the bond length or through the Mayer parameter, revealed to be probes sensitive to the presence of weak interactions: both the $\mathrm{XB}$ and $\mathrm{HB}$ have the same effect of decreasing $n_{\mathrm{CSe}}$ and increasing $n_{\mathrm{CN}}$. NPA charges corroborate the same hypothesis, with $q_{\text {Se }}$ going from -0.249 to -0.484 e in the isolated $\mathbf{S e U}$ and in the BzO-SeU adduct, respectively, whereas the energy of the $\mathrm{D} \rightarrow$ A interaction between the selenium and the C-I bond doubles up when a HB is present.

Therefore, the presence of a HB acceptor close to the amino group of SeU polarizes the latter, making the resonance structure in which the selenium is negatively charged more important and, consequently, enhancing the Lewis basicity and the XB acceptor properties of the selenium. The NBO analysis also allowed to estimate the strength of an additional, weak HB between the iodine and the $\mathrm{NH}$, but this contribution is depressed by the presence of the benzoate.

The results presented here allow to better understand the basic mechanism of cooperativity between different interactions and will contribute to the rational design of supramolecular systems for specific goals in solution, as anion sensing and weak interactions-aided catalysis.

\section{Experimental section}

All solvents and chemicals were purchased from Sigma-Aldrich and Cortecnet at the highest purity available and used as received. 1D and 2D NMR spectra were measured at $298 \mathrm{~K}$ on a Bruker DRX Avance 400 spectrometer equipped with a BBFO probe. Referencing is relative to residual of undeuterated solvents $\left({ }^{1} \mathrm{H}\right)$ and $\mathrm{CCl}_{3} \mathrm{~F}\left({ }^{19} \mathrm{~F}\right)$.

Diffusion NMR. ${ }^{1} \mathrm{H}$ diffusion NMR measurements were performed by using the double-stimulated echo sequence with longitudinal eddy current delay at $298 \mathrm{~K}$ without spinning. ${ }^{48}$ The dependence of the resonance intensity $(I)$ on a constant waiting time and on a varied gradient strength $G$ is described by the following equation:

$$
\ln \left(\mathrm{I} / \mathrm{I}_{0}\right)=(\gamma \delta)^{2} D_{\mathrm{t}}(\Delta-\delta / 3) G^{2}
$$


where $I$ is the intensity of the observed spin echo, $I_{0}$ the intensity of the spin echo in the absence of gradient, $D_{\mathrm{t}}$ the self-diffusion coefficient, $\Delta$ the delay between the midpoints of the gradients $(0.2 \mathrm{~s})$, $\delta$ the length of the gradient pulse ( $4 \mathrm{~ms})$, and $\gamma$ the magnetogyric ratio. The shape of the gradients was rectangular, and their strength $G$ was varied during the experiments.

The self-diffusion coefficient $D_{\mathrm{t}}$, was estimated by evaluating the proportionality constant for a sample of $\mathrm{HDO}(5 \%)$ in $\mathrm{D}_{2} \mathrm{O}$ (known diffusion coefficients in the range 274-318 $\mathrm{K}^{49}$ ) under the exact same conditions as the sample of interest. The solvent or TMS was taken as internal standard. The hydrodynamic volume of the species has been calculated from the experimental value of $D_{\mathrm{t}}$ through the procedure previously described. ${ }^{50}$

${ }^{1}$ H EXSY NMR. For EXSY NMR spectra, the noesygpph sequence has been employed, ${ }^{51,52}$ at 298 $\mathrm{K}$ without spinning. The mixing time was $0.6 \mathrm{~s}$.

Computational Details. All the geometries were optimized with ORCA $3.0 .3,{ }^{53}$ using the BP86 ${ }^{54,55}$ functional in conjunction with an augmented triple- $\zeta$ quality basis set. The dispersion contribution were taken into account using the Grimme D3 correction with Becke-Jonhson damping to the DFT energy. ${ }^{56}$ The energies of the optimized geometries have been successively evaluated by the M062X functional $^{57}$ and the same basis set. The solvent (acetone) has been taken into account using the COSMO solvation model. ${ }^{58}$ All the structures have been confirmed to be local energy minima (no imaginary frequencies). Thermodynamic properties have been computed at the aug-TZVP/BP86-D3 level of theory and calculated at $298 \mathrm{~K}$. Zero point energy corrections are included. NBO analysis has been performed using the NBO6 suite of software. ${ }^{59}$

\section{Acknowledgements.}

University of Pisa is gratefully acknowledged for financial support. This manuscript is part of the scientific activity of the international multidisciplinary "SeS Redox and Catalysis" network. GC thanks Clark Landis for useful discussion.

\section{References and Notes}

Supporting information available: experimental data for titrations, diffusion NMR experiments, NBO additional analysis, gas-phase energies for all the adducts and DFT-optimized geometries.

1 G. R. Desiraju, P. S. Ho, L. Kloo, A. C. Legon, R. Marquardt, P. Metrangolo, P. Politzer, G. Resnati and K. Rissanen, Definition of the halogen bond (IUPAC Recommendations 2013), Pure Appl. Chem., 2013, 85, 1711-1713.

2 G. Cavallo, P. Metrangolo, R. Milani, T. Pilati, A. Priimagi, G. Resnati and G. Terraneo, The 
halogen bond, Chem. Rev., 2016, 116, 2478-2601.

3 A. Bruckmann, M. Pena and C. Bolm, Organocatalysis through Halogen-Bond Activation, Synlett, 2008, 2008, 900-902.

4 L.-Y. You, S.-G. Chen, X. Zhao, Y. Liu, W.-X. Lan, Y. Zhang, H.-J. Lu, C.-Y. Cao and Z.-T. $\mathrm{Li}, \mathrm{C} \delta \mathrm{H} \cdots \mathrm{O}$ Hydrogen Bonding Induced Triazole Foldamers: Efficient Halogen Bonding Receptors for Organohalogens, Angew. Chemie Int. Ed., 2012, 51, 1657-1661.

5 M. R. Scholfield, C. M. Vander Zanden, M. Carter and P. S. Ho, Halogen bonding (Xbonding): A biological perspective, Protein Sci., 2013, 22, 139-152.

6 A. Mukherjee, S. Tothadi and G. R. Desiraju, Halogen Bonds in Crystal Engineering: Like Hydrogen Bonds yet Different, Acc. Chem. Res., 2014, 47, 2514-2524.

7 C. B. Aakeröy, T. K. Wijethunga and J. Desper, Practical crystal engineering using halogen bonding: A hierarchy based on calculated molecular electrostatic potential surfaces, J. Mol. Struct., 2014, 1072, 20-27.

8 O. Hassel, J. Hvoslef, E. H. Vihovde and N. A. Sörensen, The Structure of Bromine 1,4Dioxanate., Acta Chem. Scand., 1954, 8, 873-873.

9 C. B. Aakeröy, S. Panikkattu, P. D. Chopade and J. Desper, Competing hydrogen-bond and halogen-bond donors in crystal engineering, CrystEngComm, 2013, 15, 3125-3136.

10 B. K. Saha, A. Nangia and M. Jaskólski, Crystal engineering with hydrogen bonds and halogen bonds, CrystEngComm, 2005, 7, 355.

11 R. Montis, M. Arca, M. C. Aragoni, A. Bauzá, F. Demartin, A. Frontera, F. Isaia, V. Lippolis, N. Bricklebank, M. Schröder, C. Wilson and G. Verani, Hydrogen- and halogenbond cooperativity in determining the crystal packing of dihalogen charge-transfer adducts: a study case from heterocyclic pentatomic chalcogenone donors, CrystEngComm, 2017, 19, 4401-4412.

12 M. Erdélyi, Halogen bonding in solution, Chem. Soc. Rev., 2012, 41, 3547.

13 P. Thordarson, Determining association constants from titration experiments in supramolecular chemistry, Chem. Soc. Rev., 2011, 40, 1305-1323.

14 J. E. A. Webb, M. J. Crossley, P. Turner and P. Thordarson, Pyromellitamide aggregates and their response to anion stimuli, J. Am. Chem. Soc., 2007, 129, 7155-7162.

15 F. Zapata, A. Caballero, N. G. White, T. D. W. Claridge, P. J. Costa, V. Félix and P. D. Beer, Fluorescent Charge-Assisted Halogen-Bonding Macrocyclic Halo-Imidazolium Receptors for Anion Recognition and Sensing in Aqueous Media, J. Am. Chem. Soc., 2012, 134, 1153311541.

16 G. Ciancaleoni, R. Bertani, L. Rocchigiani, P. Sgarbossa, C. Zuccaccia and A. Macchioni, 
Discriminating Halogen-Bonding from Other Noncovalent Interactions by a Combined NOE NMR/DFT Approach, Chem. - A Eur. J., 2015, 21, 440-447.

17 L. C. Gilday and P. D. Beer, Halogen- and Hydrogen-Bonding Catenanes for Halide-Anion Recognition, Chem. - A Eur. J., 2014, 20, 8379-8385.

18 C. J. Serpell, N. L. Kilah, P. J. Costa, V. Félix and P. D. Beer, Halogen Bond Anion Templated Assembly of an Imidazolium Pseudorotaxane, Angew. Chemie Int. Ed., 2010, 49, 5322-5326.

19 G. Ciancaleoni, A. Macchioni, L. Rocchigiani and C. Zuccaccia, A PGSE NMR approach to the characterization of single and multi-site halogen-bonded adducts in solution, RSC Adv., 2016, 6, 80604-80612.

20 L. Maugeri, J. Asencio-Hernández, T. Lébl, D. B. Cordes, A. M. Z. Slawin, M.-A. Delsuc and D. Philp, Neutral iodotriazoles as scaffolds for stable halogen-bonded assemblies in solution, Chem. Sci., 2016, 7, 6422-6428.

21 G. Ciancaleoni, Characterization of Halogen Bonded Adducts in Solution by Advanced NMR Techniques, Magnetochemistry, 2017, 3, 30.

22 R. Tepper, B. Schulze, P. Bellstedt, J. Heidler, H. Görls, M. Jäger and U. S. Schubert, Halogen-bond-based cooperative ion-pair recognition by a crown-ether-embedded 5-iodo1,2,3-triazole, Chem. Commun., 2017, 53, 2260-2263.

23 A. Mele, P. Metrangolo, H. Neukirch, T. Pilati and G. Resnati, A halogen-bonding-based heteroditopic receptor for alkali metal halides, J. Am. Chem. Soc., 2005, 127, 14972-14973.

24 M. D. Esrafili, J. Beheshtian and N. L. Hadipour, Computational study on the characteristics of the interaction in linear urea clusters, Int. J. Quantum Chem., 2011, 111, 3184-3195.

25 X. C. Yan, P. Schyman and W. L. Jorgensen, Cooperative effects and optimal halogen bonding motifs for self-assembling systems, J. Phys. Chem. A, 2014, 118, 2820-2826.

26 J. George, V. L. Deringer and R. Dronskowski, Cooperativity of halogen, chalcogen, and pnictogen bonds in infinite molecular chains by electronic structure theory, J. Phys. Chem. A, 2014, 118, 3193-3200.

27 M. Solimannejad, M. Malekani and I. Alkorta, Substituent Effects on the Cooperativity of Halogen Bonding, J. Phys. Chem. A, 2013, 117, 5551-5557.

28 M. D. Esrafili and P. Mousavian, Unusual cooperativity effects between halogen bond and donor-acceptor interactions: The role of orbital interaction, Chem. Phys. Lett., 2017, 678, $275-282$.

29 I. Alkorta, F. Blanco, P. M. Deyà, J. Elguero, C. Estarellas, A. Frontera and D. Quiñonero, Cooperativity in multiple unusual weak bonds, Theor. Chem. Acc., 2010, 126, 1-14. 
30 S. Kozuch and J. M. L. Martin, Halogen bonds: Benchmarks and theoretical analysis, J. Chem. Theory Comput., 2013, 9, 1918-1931.

31 L. Goerigk, A. Hansen, C. A. Bauer, S. Ehrlich, A. Najibi, and S. Grimme, A Look at the Density Functional Theory Zoo with the Advanced GMTKN55 Database for General Main Group Thermochemistry, Kinetics and Noncovalent Interactions. Phys. Chem. Chem. Phys., 2017, 19, 32184-32215.

32 M. von Hopffgarten and G. Frenking, Energy decomposition analysis, Wiley Interdiscip. Rev. Comput. Mol. Sci., 2012, 2, 43-62.

33 L. Belpassi, I. Infante, F. Tarantelli and L. Visscher, The chemical bond between Au(I) and the noble gases. Comparative study of $\mathrm{NgAuF}$ and $\mathrm{NgAu}+(\mathrm{Ng}=\mathrm{Ar}, \mathrm{Kr}, \mathrm{Xe})$ by density functional and coupled cluster methods, J. Am. Chem. Soc., 2008, 130, 1048-1060.

34 G. Ciancaleoni, L. Biasiolo, G. Bistoni, A. Macchioni, F. Tarantelli, D. Zuccaccia and L. Belpassi, Selectively measuring $\Pi$ back-donation in gold(I) complexes by NMR spectroscopy, Chem. - A Eur. J., 2015, 21, 2467-2473.

35 R. F. W. Bader, Atoms in molecules, Acc. Chem. Res., 1985, 18, 9-15.

36 R. Cabot and C. A. Hunter, Non-covalent interactions between iodo-perfluorocarbons and hydrogen bond acceptors, Chem. Commun., 2009, 2005.

37 C. C. Robertson, R. N. Perutz, L. Brammer and C. A. Hunter, A solvent-resistant halogen bond, Chem. Sci., 2014, 5, 4179-4183.

38 D. Zuccaccia, G. Bellachioma, G. Cardaci, G. Ciancaleoni, C. Zuccaccia, E. Clot and A. Macchioni, Interionic structure of ion pairs and ion quadruples of half-sandwich ruthenium(II) salts bearing a-diimine ligands, Organometallics, 2007, 26, 3930-3946.

39 J. P. Fackler and L. Falvello, Techniques in inorganic chemistry, CRC Press/Taylor \& Francis, 2011.

40 P. S. Pregosin, in Spectroscopic Properties of Inorganic and Organometallic Compounds: Techniques, Materials and Applications, Volume 42, The Royal Society of Chemistry, 2012, vol. 42, pp. 248-268.

41 G. Ciancaleoni, C. Zuccaccia, D. Zuccaccia and A. Macchioni, Combining diffusion NMR and conductometric measurements to evaluate the hydrodynamic volume of ions and ion pairs, Organometallics, 2007, 26, 3624-3626.

42 Q. Jin Shen and W. Jun Jin, Strong halogen bonding of 1,2-diiodoperfluoroethane and 1,6diiodoperfluorohexane with halide anions revealed by UV-Vis, FT-IR, NMR spectroscopes and crystallography, Phys. Chem. Chem. Phys., 2011, 13, 13721.

43 V. Amendola, L. Fabbrizzi and L. Mosca, Anion recognition by hydrogen bonding: urea- 
based receptors, Chem. Soc. Rev., 2010, 39, 3889.

44 A. Casula, P. Begines, A. Bettoschi, J. G. Fernandez-Bolaños, F. Isaia, V. Lippolis, Ó. López, G. Picci, M. Andrea Scorciapino and C. Caltagirone, Selenoureas for anion binding as molecular logic gates, Chem. Commun., 2017, 53, 11869-11872.

45 Since B-S is a supramolecular anion, an approximation is required: the ion pairing process between $\mathbf{T B A}^{+}$and $(\mathbf{B}-\mathbf{S})^{-}$is considered constant, which is likely as $[\mathbf{B}-\mathbf{S}]$ does not change during the titration.

46 X. Lucas, C. Estarellas, D. Escudero, A. Frontera, D. Quiñonero and P. M. Deyà, Very longrange effects: Cooperativity between Anion- $\pi$ and hydrogen-bonding interactions, ChemPhysChem, 2009, 10, 2256-2264.

47 A. J. Bridgeman, G. Cavigliasso, L. R. Ireland and J. Rothery, The Mayer bond order as a tool in inorganic chemistry, J. Chem. Soc. Dalt. Trans., 2001, 2095-2108.

48 N. M. Alexej Jerschow, Suppression of Convection Artifacts in Stimulated-Echo Diffusion Experiments. Double-Stimulated-Echo Experiments, J. Magn. Reson., 1997, 375, 372-375.

49 R. Mills, Self-diffusion in normal and heavy water in the range 1-45.deg., J. Phys. Chem., $1973,77,685-688$.

50 A. Macchioni, G. Ciancaleoni, C. Zuccaccia and D. Zuccaccia, Determining accurate molecular sizes in solution through NMR diffusion spectroscopy, Chem. Soc. Rev., 2008, 37, 479-489.

51 J. Jeener, B. H. Meier, P. Bachmann and R. R. Ernst, Investigation of exchange processes by two-dimensional NMR spectroscopy, J. Chem. Phys., 1979, 71, 4546-4553.

52 R. Wagner and S. Berger, Gradient-selected NOESY-A fourfold reduction of the measurement time for the noesy experiment, J. Magn. Reson. - Ser. A, 1996, 123, 119-121.

53 F. Neese, The ORCA program system, Wiley Interdiscip. Rev. Comput. Mol. Sci., 2012, 2, $73-78$.

54 A. D. Becke, Density-functional exchange-energy approximation with correct asymptotic behavior, Phys. Rev. A, 1988, 38, 3098-3100.

55 J. P. Perdew, Density-functional approximation for the correlation energy of the inhomogeneous electron gas, Phys. Rev. B, 1986, 33, 8822-8824.

56 S. Grimme, J. Antony, S. Ehrlich and H. Krieg, A consistent and accurate ab initio parametrization of density functional dispersion correction (DFT-D) for the 94 elements HPu, J. Chem. Phys., 2010, 132, 154104.

57 Y. Zhao and D. G. Truhlar, The M06 suite of density functionals for main group thermochemistry, thermochemical kinetics, noncovalent interactions, excited states, and 
transition elements: Two new functionals and systematic testing of four M06-class functionals and 12 other function, Theor. Chem. Acc., 2008, 120, 215-241.

58 Klamt, A. and G. Schüürmann, COSMO: a new approach to dielectric screening in solvents with explicit expressions for the screening energy and its gradient. J. Chem. Soc., Perkin Trans. 2, 1993, 0, 799-805.

59 NBO 6.0. E. D. Glendening, J. K. Badenhoop, A. E. Reed, J. E. Carpenter, J. A. Bohmann, C. M. Morales, C. R. Landis, and F. Weinhold (Theoretical Chemistry Institute, University of Wisconsin, Madison, WI, 2013); http://nbo6.chem.wisc.edu/. 